\title{
Hiperplasia epitelial focal (doença de Heck) em descendente de indios brasileiros: relato de caso
}

\section{Focal epithelial hyperplasia (Heck's disease) in Brazilian indian descent: report of a case}

Pedro Paulo de Andrade Santos ${ }^{1}$; Marcelo Gadelha Vasconcelos'; Karuza Maria Alves Pereira²; Lélia Batista de Souza ${ }^{3}$; Roseana de Almeida Freitas ${ }^{3}$; Antônio de Lisboa Lopes Costa ${ }^{4}$; Ana Myriam Costa de Medeiros ${ }^{5}$

\section{unitermos}

Hiperplasia epitelial focal

Doença de Heck

Papilomavírus humano

\section{resumo}

A hiperplasia epitelial focal, ou doença de Heck, é uma enfermidade rara, benigna, que afeta a mucosa oral de crianças e adultos jovens de diversas regiões do mundo e em diferentes grupos étnicos, como indígenas e esquimós. Apresenta correlação com o papilomavírus humano (HPV) no qual os tipos 13 e 32 têm sido consistentemente detectados nessas lesões. Este artigo relata um caso de uma paciente de 18 anos de idade, descendente de índios potiguares, que compareceu ao serviço de estomatologia da Universidade Federal do Rio Grande do Norte (UFRN), exibindo lesões bem definidas, arredondadas, planas, localizadas em cavidade oral, com tempo de evolução de aproximadamente dois anos. As lesões foram submetidas a biópsias incisionais, constatado-se no exame histopatológico alterações epiteliais, como acantose, cristas epiteliais em forma de "taco de golfe" além de células mitosóides. Esses achados histopatológicos foram compatíveis com a hipótese clínica de hiperplasia epitelial focal (doença de Heck).

\section{abstract}

The focal epithelial hyperplasia or Heck's disease is a benign rare pathology, that affects children and young adults oral mucosal in many world regions, and different ethnic groups, for example Indians and Eskimos. Presents correlation with the subtypes 13 and 32 of human papillomavirus (HPV). This article report a case of an 18-year-old patient, descent of potiguar indian, attended in stomatology service of Federal University of Rio Grande do Norte (UFRN), presenting well defined lesions, round, plane, localized in oral cavity with an evolution of two years. The lesions were submitted to incisional biopsies, verifying in histopathologic exam, epithelial alterations, like acanthosis, epithelial projections in "parquet block of golf" beyond mitosoid cells. These histopathological findings were compatible with clinical hypothesis of focal epithelial hyperplasia (Heck's disease). key words

Focal epithelial hyperplasia

Heck's disease

Human papillomavirus

\section{Introdução}

A hiperplasia epitelial focal é uma proliferação induzida por vírus, localizada no epitélio escamoso oral, e foi descrita pela primeira vez (1894) em esquimós da Groelândia. Posteriormente, em 1965, foi relatada em latino-americanos e americanos nativos. Hoje se sabe que esse quadro clínico está presente em muitas populações e em diferentes grupos étnicos. O corrente termo doença de Heck foi estabelecido em homenagem ao Dr. John Heck, que identificou o paciente com essa condição no Novo México, em $1961^{(1,3,8,13)}$.

1. Alunos do curso de mestrado do Programa de Pós-graduação em Patologia Oral da Universidade Federal do Rio Grande do Norte (UFRN)

2. Aluna do curso de doutorado do Programa de Pós-graduação em Patologia Oral da UFRN.

3. Professora-doutora do Programa de Pós-graduação em Patologia Oral da UFRN.

4. Professor-doutor do Programa de Pós-graduação em Patologia Oral da UFRN.

5. Professora-doutora da disciplina Diagnóstico Oral da UFRN.

Trabalho realizado no Departamento de Odontologia da UFRN - Programa de Pós-graduação em Patologia Oral. 
Os locais mais propensos ao desenvolvimento dessa lesão são as superfícies ceratinizadas e não-ceratinizadas nas quais tem sido observada relação com dois tipos de papilomavírus humano (HPV): o HPV 32, com tendência a causar doença em pessoas de mais idade, e o HPV 13, que parece estar igualmente envolvido no desenvolvimento da doença, tanto em pacientes jovens quanto nos de idade mais avançada ${ }^{(7,11,12)}$.

A doença de Heck é clinicamente caracterizada por lesões bem definidas, que podem ser únicas ou múltiplas, como nódulos ou pápulas, arredondadas ou planas, que freqüentemente coalescem, e tamanho variando entre 0,1 e $1 \mathrm{~cm}$ de diâmetro. São indolores em sua maioria, localizando-se principalmente nas mucosas jugal, labial, lingual, gengival e, com menor freqüência, no assoalho

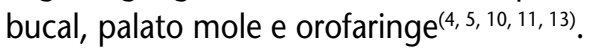

O relato de caso deste artigo descreve a ocorrência da hiperplasia epitelial focal (doença de Heck) em uma paciente de 18 anos de idade, que compareceu ao Serviço de Estomatologia da Universidade Federal do Rio Grande do Norte (UFRN) no qual foi examinada e confirmada a hipótese diagnóstica para essa entidade por meio de exame histopatológico.

\section{Relato de caso}

Paciente, sexo feminino, 18 anos de idade, cor leucoderma, compareceu à clínica de estomatologia do Departamento de Odontologia da UFRN queixando-se que, aproximadamente, há 2 anos tem observado a presença de bolinhas (sic) em sua boca as quais se tornavam cada vez mais visíveis, mas sem a ocorrência de dor.

O exame clínico revelou nódulos de superfície lisa, em sua maioria séssil, embora alguns se apresentassem pediculados, exibindo formas arredondadas nas quais muitos coalesciam, com coloração variada nas áreas esbranquiçadas, mas essas áreas exibiam a mesma coloração da mucosa em sua maioria. As lesões eram firmes à palpação, revestidas por uma mucosa aparentemente normal, sem úlceras ou inflamação, com tamanho variando entre 0,5 e $1 \mathrm{~cm}$, e localização nas mucosas jugal (bilateralmente) e na interna dos lábios (Figuras 1 e 2).

Questionada sobre sua origem étnica/familiar, a paciente relatou que seus bisavós maternos eram índios e que a maioria dos seus familiares possuía características indígenas, contudo nenhum deles apresentava esse tipo de lesão na boca. A paciente referiu vida sexualmente ativa, sendo então devidamente encaminhada para avaliação médica, mas não foram observadas lesões semelhantes em outras localizações, como vagina e região anal.

De acordo com os achados clínicos foi proposta a hipótese diagnóstica de hiperplasia epitelial oral focal (doença de

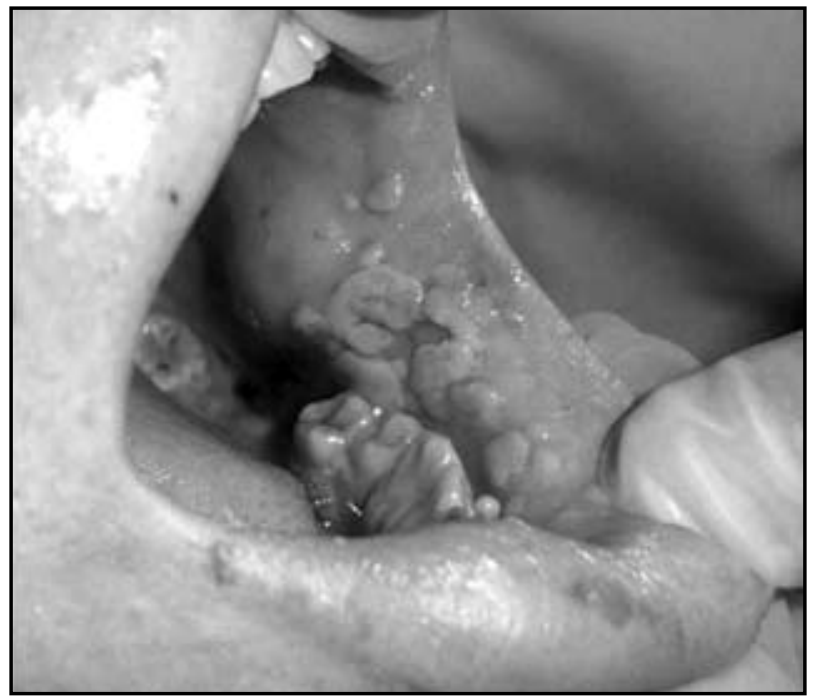

Figura 1 - Exame intra-oral evidenciando na mucosa jugal múltiplos nódulos de tamanho variado, alguns dos quais coalesciam

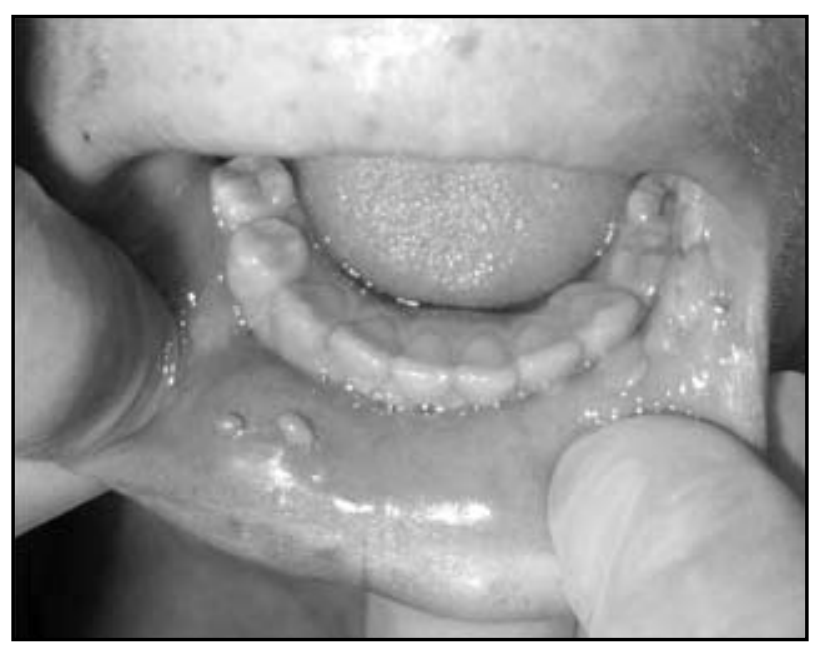

Figura 2 - Nódulos de superfície lisa na mucosa interna do lábio inferior

Heck). Para confirmar essa hipótese diagnóstica, a paciente foi submetida a duas biópsias incisionais, uma realizada na mucosa jugal esquerda, pois apresentava lesões de maior tamanho, e a outra no lábio inferior.

O exame histopatológico utilizando coloração de rotina pela hematoxilina-eosina (HE) revelou proliferação epitelial com acantose proeminente (Figura 3), alterações epiteliais, como presença de coilócitos, células mitosóides ocasionais (Figura 4), e focos hiperplásicos com projeções confluentes para o tecido conjuntivo, sendo algumas dessas em forma de "taco de golfe" (Figura 5). Esses achados histopatológicos foram compatíveis com a hipótese clínica de doença de Heck.

\section{Discussão}

A hiperplasia epitelial focal ocorre freqüentemente em indígenas, entretanto têm sido relatados alguns outros gru- 


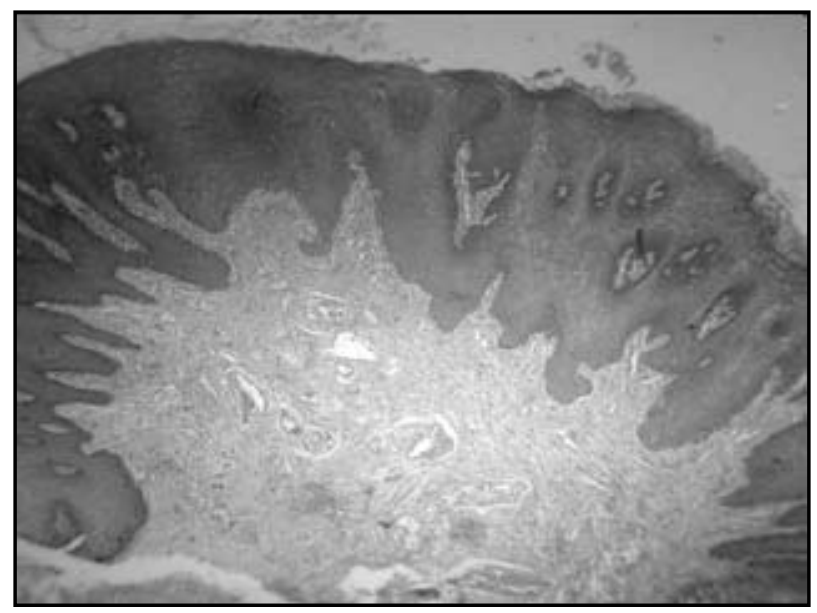

Figura 3 - Fotomicrografia exibindo proliferação epitelial com acantose proeminente (HE 40x)

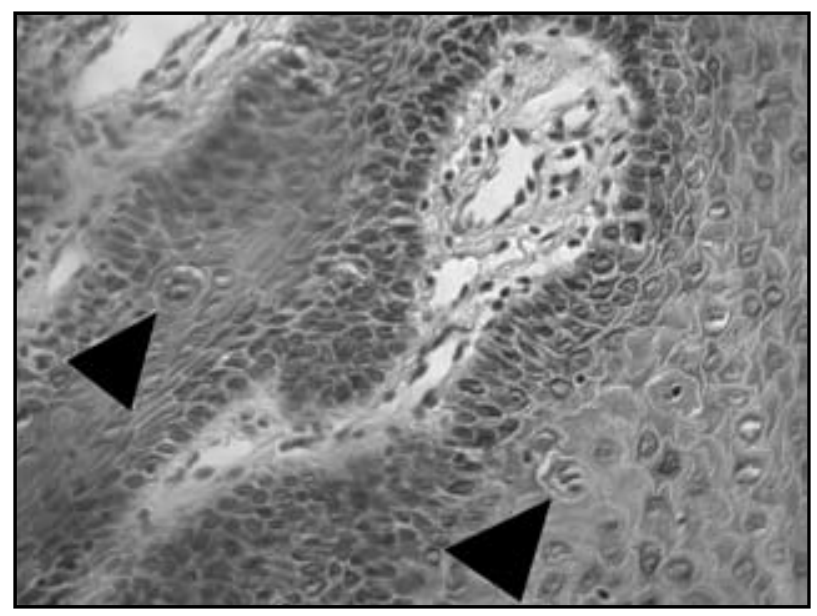

Figura 4 - Fotomicrografia na qual são evidenciadas células mitosóides (HE 400x)

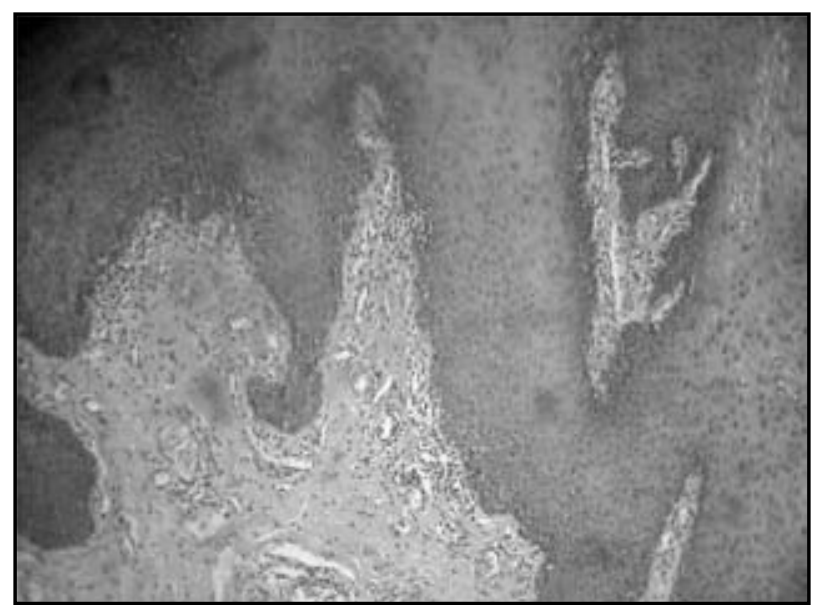

Figura 5 - Áreas hiperplásicas no epitélio emitindo projeções para conjuntivo, algumas dessas semelhantes a "taco de golfe" (HE 100x)

pos étnicos. Na maioria dos casos publicados desde 1965, essa entidade é observada em esquimós e em índios das Américas do Norte, Central e do Sul, como, por exemplo, em índios Xavantes do Brasil. Poucos casos foram reportados fora das Américas, sendo relatados um no Japão, parcos casos em caucasianos da Suécia e da Noruega, e em negros do continente africano.

A doença de Heck é caracterizada por apresentar curso benigno e resolução espontânea em poucos anos, porém alguns relatos têm apresentado casos com curso clínico de 20 anos $^{(6,8)}$. No caso em questão, a paciente apresenta essas lesões com dois anos de evolução. Além disso, ela é de descendência indígena, o que está de acordo com a literatura anteriormente citada.

Há relatos de lesões papilares verruciformes e nodulares não só na mucosa oral como também nas regiões anal e genital. Assim, relacionando a presença dessa doença a certos grupos étnicos, podemos afirmar que é provável existir um co-fator genético ${ }^{(15)}$. Também sabemos da relação de subtipos do HPV 13 e/ou 32 com essa doença, o que pode ser demonstrado por estudos imuno-histoquímicos e, mais recentemente, utilizando hibridização in situ $^{(9)}$. As lesões descritas foram observadas na mucosa oral da paciente, que foi encaminhada para avaliação médica, mas não foram constatadas lesões na vagina ou na região anal.

Há necessidade da realização de um diagnóstico diferencial com outras doenças, como hiperplasia fibrosa inflamatória, hiperplasia papilar inflamatória, xantoma verruciforme, carcinoma verrucoso, doença de Cowden e condiloma acuminado ${ }^{(16)}$.

As três primeiras mencionadas são lesões reacionais as quais, na maioria dos casos, um agente irritante pode ser identificado. Já o carcinoma verrucoso é uma neoplasia que incide numa faixa etária diferente, com características epidemiológicas encontradas em carcinomas orais. A doença de Cowden, típica de um grupo etário com idade mais avançada, apresenta pólipos fibroepiteliais mais consistentes, com menor mobilidade, e diferente topografia intra-oral. É importante que seja feito o diagnóstico diferencial com o condiloma acuminado devido a sua apresentação clínica, com lesões isoladas muito semelhantes, tanto no condiloma quanto na hiperplasia epitelial focal, visto que ambas são causadas pelo HPV. Entretanto, as lesões encontradas na hiperplasia epitelial focal tendem a ser planas e mais numerosas, adicionando-se o fato de a localização dessas lesões em lábio e mucosa jugal ser muito característica ${ }^{(3)}$.

Microscopicamente a hiperplasia epitelial na doença de Heck apresenta uma considerável e abrupta acantose focal. O espessamento do epitélio se estende para a superfície externa da lesão, com as cristas epiteliais da lesão se apresentando na mesma profundidade das cristas epiteliais normais adjacentes. As cristas epiteliais são mais largas, freqüentemente confluentes e, algumas vezes, em forma de "taco de golfe". Podemos observar, ainda, alterações coilocíticas em alguns ceratinócitos superficiais semelhantes a outras infecções pelo HPV, bem como células mitosóides (células com núcleo alterado) que lembram uma figura de mitose $(7,8,13)$. 
Num estudo realizado constatou-se a necessidade de cortes seriados para se identificar as células mitosóides, pois as mesmas podem não estar presentes em um único corte ${ }^{(4)}$. Estudos recentes têm indicado a presença de hiperplasia epitelial focal em pacientes infectados pelo $\operatorname{HIV}(7,9,13)$.

Os achados histopatológicos referentes às alterações epiteliais detectadas neste caso correspondem àqueles descritos comumente na literatura pertinente. Histopatologicamente podemos diferenciar do papiloma e de outras lesões papilomatosas pelo fato de a hiperplasia epitelial focal não exibir projeções epiteliais para a superfície externa do epitélio e também devido à presença das células mitosóides ${ }^{(7)}$.

Este caso relatado parece apresentar uma forte relação com sua predisposição genética para a hiperplasia epitelial focal, visto que a paciente é descendente de índios brasileiros.
O tratamento da hiperplasia epitelial focal varia desde 0 simples acompanhamento do caso, uma vez que a doença tende a regredir espontaneamente e/ou pode persistir por muitos anos, até o tratamento cirúrgico que fica restrito aos casos em que há comprometimento estético ${ }^{(8,13,14)}$. Entretanto, existem alternativas para o tratamento, como crioterapia, laserterapia ${ }^{(1,7)}$, cauterização e utilização de tratamentos tópicos, como ácido retinóico ou interferon ${ }^{(1)}$.

Neste caso optamos pelo acompanhamento da paciente, pois há relatos na literatura de regressão espontânea após meses ou anos e parece não haver potencial de transformação maligna. Assim, a excisão cirúrgica está indicada apenas para fins de diagnóstico, estéticos, ou quando as lesões interferirem na função mastigatória ou forem constantemente submetidas a trauma, já que a recorrência é mínima.

\section{Referências}

1. AKNOL, A. et al. Multifocal papillomavirus epithelial hyperplasia: sucessful treatment with $\mathrm{CO}_{2}$ laser therapy combined with interferon alpha-2b. Int J Dermatol, v.42, p.733-5, 2003.

2. ARCHARD, H.O. et al. Focal epithelial hyperplasia: an unusual oral mucosa lesion found in Indian children. Oral Surg Oral Med Oral Pathol Oral Radiol Endod, v. 20, p. 201-12, 1965.

3. BORBOREMA-SANTOS, C.M. et al. Oral focal epithelial hyperplasia: report of five cases. Braz Dent J, v. 17, n. 1, p.79-82, 2006.

4. CARLOS, R.; SEDANO, H.O. Multi focal papilomavirus epithelial hyperplasia. Oral Surg Oral Med Oral Pathol, v. 77, p. 631-5, 1994.

5. CUBEROS, V. et al. Molecular and serological evidence of the epidemiological association of HPV 13 with focal epithelial hyperplasia: a case-control study. J Clin Virol, v. 37, p. 21-6, 2006.

6. GONZÁLEZ, L.V. et al. Clinical, histopathological and virological findings in patients with focal epithelial hyperplasia from Colombia. Int J Dermatol. v. 44, p. 274-9, 2005.

7. JAYASOORIYA, P.R.; RANASINGHE, A.W.; TILAKARATNE, W.M. Focal epithelial hyperplasia (Heck's disease): report of two cases with PCR detection of human papillomavirus DNA. Oral Dis, v. 10, p. 240-3, 2004.

8. MARTINS, W.D.; DE LIMA, A.A.S.; VIEIRA, S. Focal epithelial hyperplasia (Heck's disease): report of a case in a girl of Brazilian Indian descent. Int J Paediatr Dent, v. 16, p. 65-8, 2006.

9. MARVAN, E.; FIRTH, N. Focal epithelial hyperplasia in an HIV positive man: an illustrated case report and review of literature. Aust Dent J, v. 43, p. 305-10, 1998.

10. MEALEY, B.L.; HALLMON, W.W.; WALDROP, T.C. Occurrence and resolution of focal epithelial hyperplasia in two siblings with leukocyte adhesion deficiency. J Periodontol, v. 64, p. 149-52, 1993.

11. MORROW. D.J. SANDHU, H.S.; DALEY, T.D. Focal epithelial hyperplasic (Heck's disease) with generalized lesions on the gingiva: a case report. J Periodontol, v. 64, p. 63-5, 1993.

12. NELSON, B.L.; SCHAFER, D.R.; BOSY, T.Z. The typing of the human papillomavirus within an older patient population. J Dent Res, Abstract 0897, 2002

13. NEVILLE, B.W. et al. Patologia epitelial. In: Patologia oral \& maxilofacial. 2 ed. Rio de Janeiro: Guanabara Koogan, 2004; p. 308-9.

14. SAINT-GERONS, R.S. et al. Hiperplasia epitelial focal: uma rara enfermedad en nuestro medio. Med Oral Patol Oral Cir Bucal, v. 10, p. 128-31, 2005.

15. STEINHOFF, M. et al. Sucessful topical treatment of focal epithelial hyperplasia (Heck's disease) with interferon- $\beta$. Br J Dermatol, v. 144, p. 1067-9, 2001.

16. TEREZHALMY, G.T. RILEY, C.K.; MOORE W.S. Focal epithelial hyperplasia (Heck's disease). Quintessence Int, v. 32, p. 664-5, 2001.

\begin{tabular}{l|l} 
& Endereço para correspondência \\
\hline & Roseana de Almeida Freitas \\
& Departamento de Odontologia \\
Av. Senador Salgado Filho, 1787 - Lagoa Nova \\
CEP: 59056-000 - Natal-RN \\
Tel.: (084) 3215-4132 \\
Tel./fax: (084) 3215-4138 \\
e-mail: roseana@dod.ufrn.br - pedropauloodonto@yahoo.com.br
\end{tabular}

